\title{
Chemical Phase Separation of Superconductive and Ferromagnetic Domains in $\mathrm{ZnNNi}_{3-x} \mathrm{Co}_{x}$
}

\author{
Takahiro Yamazaki, Akira Uehara, Katsuya Kozawa, \\ Yoshihide Kimisima, and Masatomo Uehara \\ Department of Physics, Faculty of Engineering, Yokohama National University, Hodogaya-ku, Yokohama 240-8501, Japan \\ Correspondence should be addressed to Masatomo Uehara, uehara@ynu.ac.jp
}

Received 19 September 2012; Accepted 12 December 2012

Academic Editor: Cong Wang

Copyright $\odot 2012$ Takahiro Yamazaki et al. This is an open access article distributed under the Creative Commons Attribution License, which permits unrestricted use, distribution, and reproduction in any medium, provided the original work is properly cited.

\begin{abstract}
Various $\mathrm{ZnN}_{y} \mathrm{Ni}_{3-x} \mathrm{Co}_{x}$ compounds with differing Co content, $x$, were synthesized, and their magnetic properties were investigated. Uniform solid solutions could not be obtained at low Co content $(x<0.75)$; instead micrometer-scaled ferromagnetic $\mathrm{ZnN}_{y} \mathrm{Ni}_{0.6} \mathrm{Co}_{2.4}$ domains formed embedded within a superconductive $\mathrm{ZnNNi}_{3}$ bulk, showing chemical phase separation of superconductive $\mathrm{ZnNNi}_{3}$ and ferromagnetic $\mathrm{ZnN}_{y} \mathrm{Ni}_{0.6} \mathrm{Co}_{2.4}$. At intermediate levels of Co concentration $(0.75<x<2)$, this two-phase separation might persist, and the superconductive behavior was strongly suppressed in this composition region. Only at high Co concentration $(x>2)$ the uniform ferromagnetic solid solution $\mathrm{ZnN}_{y} \mathrm{Ni}_{3-x} \mathrm{Co}_{x}$ (with most likely $y=0.5$ ) formed. The phase separation behavior is intrinsic to the system, reflecting the existence of a miscibility gap in $\mathrm{ZnN}_{y} \mathrm{Ni}_{3-x} \mathrm{Co}_{x}$ for the samples with $x<2$, and was shown not to be attributable to incomplete synthesis. In the two-phased samples, high-quality granular contact between the superconductor and ferromagnet has been realized, suggesting that the production of useful devices requiring high-quality contacts between superconductors and ferromagnets may be possible by making use of this two-phase situation.
\end{abstract}

\section{Introduction}

He et al. discovered a new antiperovskite superconductor $\mathrm{MgCNi}_{3}$ that has a superconducting transition temperature $\left(T_{c}\right) \sim 8 \mathrm{~K}[1]$. This compound has attracted attention in the context of the relationship between superconductivity and ferromagnetism, because the material includes large amounts of ferromagnetic $\mathrm{Ni}$ and has structural similarities with f.c.c. elemental Ni. Some researchers have supposed that the ferromagnetic correlation is associated with the superconductivity of $\mathrm{MgCNi}_{3}$. A theoretical calculation has pointed out that this compound is located near a ferromagnetic state and that the emergence of ferromagnetism may be induced by hole doping [2].

In order to reveal the superconducting gap symmetry and to clarify the microscopic origin of the superconductivity in $\mathrm{MgCNi}_{3}$, various types of experiments have been carried out [3-14]. However, a rigid consensus has not been obtained yet about the origin of superconductivity in $\mathrm{MgCNi}_{3}$. Stimulated by the discovery of $\mathrm{MgCNi}_{3}$, several new antiperovskite compounds have been synthesized including two new superconductors, $\mathrm{CdCNi}_{3}$ and $\mathrm{ZnNNi}_{3}$, and complementary theoretical studies have been performed, especially for these new superconductors [15-33].

In this study we synthesized and investigated the physical properties of the $\mathrm{ZnN}_{y} \mathrm{Ni}_{3-x} \mathrm{Co}_{x}$ system composed of superconductive $\mathrm{ZnNNi}_{3}$ and ferromagnetic $\mathrm{ZnN}_{y} \mathrm{Co}_{3} . \mathrm{ZnNNi}_{3}$ is a superconductor with $T_{c} \sim 3 \mathrm{~K}$ that has the same antiperovskite structure as $\mathrm{MgCNi}_{3}[34,35] . \mathrm{ZnN}_{y} \mathrm{Co}_{3}$ is a ferromagnet with a Curie temperature above room temperature. It should be mentioned that the nitrogen content $y$ of $\mathrm{ZnN}_{y} \mathrm{Co}_{3}$ is about half of that in $\mathrm{ZnNNi}_{3}(y \sim 0.5)$, which seems to be the only stable nitrogen content of this material [36]. The nitrogen content of $\mathrm{ZnN}_{y} \mathrm{Co}_{3}$ has been confirmed by measuring the weight change before and after sintering.

These two compounds have the same antiperovskite structure and almost the same lattice constant (3.756 and $3.758 \AA$ for $\mathrm{ZnNNi}_{3}$ and $\mathrm{ZnN}_{y} \mathrm{Co}_{3}$, resp.), which make them 
likely to form a $\mathrm{ZnN}_{y} \mathrm{Ni}_{3-x} \mathrm{Co}_{x}$ solid solution with a whole value of $x$. However the chemical phase separation of superconductive $\mathrm{ZnNNi}_{3}$ and ferromagnetic $\mathrm{ZnN}_{y} \mathrm{Ni}_{0.6} \mathrm{Co}_{2.4}$ domains has been observed. In this paper, we report the synthesis and the two-phase separation of superconductivity and ferromagnetism in the $\mathrm{ZnN}_{y} \mathrm{Ni}_{3-x} \mathrm{Co}_{x}$ system in detail.

\section{Experimental}

The samples were prepared from elemental $\mathrm{Zn}, \mathrm{Ni}$, and $\mathrm{Co}$ powders. The powders were weighed and mixed to a nominal composition of $\mathrm{Zn}_{1.05} \mathrm{Ni}_{3-x} \mathrm{Co}_{x}$ and were then pressed into pellets. Extra Zn powder was added to compensate for loss due to vaporization. The pellets were sintered in $\mathrm{NH}_{3}$ gas in the following temperature sequence: (1) $400^{\circ} \mathrm{C}$ for $3 \mathrm{~h}$, (2) $520^{\circ} \mathrm{C}$ for $5 \mathrm{~h}$, and (3) $550-600^{\circ} \mathrm{C}$ for $5 \mathrm{~h}$ several times with intermediate grinding steps. The $\mathrm{NH}_{3}$ gas decomposes to chemically active hydrogen and nitrogen at high temperatures, and the active nitrogen penetrates into the sample to nitrify the sample. This has been shown to be an effective method for forming 3d-transition metal nitrides [37-39].

$\mathrm{X}$-ray diffraction patterns were obtained using $\mathrm{Cu} \mathrm{K} \alpha$ radiation. The magnetization measurements were performed using a Quantum Design SQUID magnetometer. Magnetization was measured with zero-field cooling (ZFC). In order to investigate the homogeneity of the sample, an electron probe microanalyzer (EPMA) was used.

\section{Results and Discussion}

Figure 1 shows the powder X-ray diffraction patterns obtained for various $\mathrm{ZnN}_{y} \mathrm{Ni}_{3-x} \mathrm{Co}_{x}$ samples. All of the diffraction patterns indicate a cubic structure with $\mathrm{Pm} 3 \mathrm{~m}$ space group. No impurity peaks were detected, showing singlephased samples. The lattice parameters were determined to be a nearly constant value of $3.756 \AA$ for all samples, and systematic changes in the lattice constant were not observed as the $\mathrm{Ni}$ : Co ratio was varied.

Figure 2 shows the temperature dependence of the magnetic susceptibility for $\mathrm{ZnN}_{y} \mathrm{Ni}_{3-x} \mathrm{Co}_{x}$ with $x=0,0.25$, 0.5 , and 0.75 samples. All samples show superconductive behavior. The onset of $T_{c}$ was seen to slightly decreased as the Co content $(x)$ was increased. Though the superconducting volume fraction (SVF) decreases as $x$ increases, the SVF values are large enough for bulk superconductivity up to $x=0.5$ (SVF $=12 \%$ estimated from magnetization value at $1.8 \mathrm{~K}$ ). The bulk superconductivity disappears in samples with $x$ above 0.75 (data with $x>0.75$ not shown).

Figure 3 shows the field dependence of magnetization curves at $1.8 \mathrm{~K}$ and $3.5 \mathrm{~K}$ with (a) $x=0.25$ and (b) $x=$ 0.5 . Below $T_{c}(1.8 \mathrm{~K})$, the magnetization curves show superconducting character but overlap with ferromagnetic character for both samples. The ferromagnetic character becomes more obvious for the sample with larger Co content (compare $x=0.5$ data in Figures $3(\mathrm{a})$ and $3(\mathrm{~b})$ at $1.8 \mathrm{~K}$ ). At the lower temperature, superconductivity seems to coexist with ferromagnetism, but above $T_{c}(3.5 \mathrm{~K})$, the superconductive character disappears and only the ferromagnetism survives (see $3.5 \mathrm{~K}$ data of Figures 3(a) and 3(b)). In order to clarify

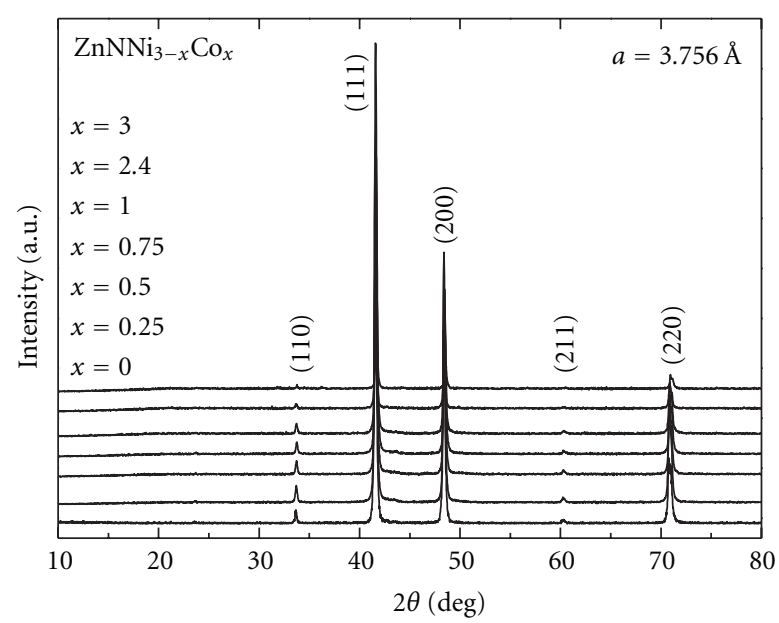

FIgURe 1: Powder X-ray diffraction pattern for $\mathrm{ZnNNi}_{3-x} \mathrm{Co}_{x}$.

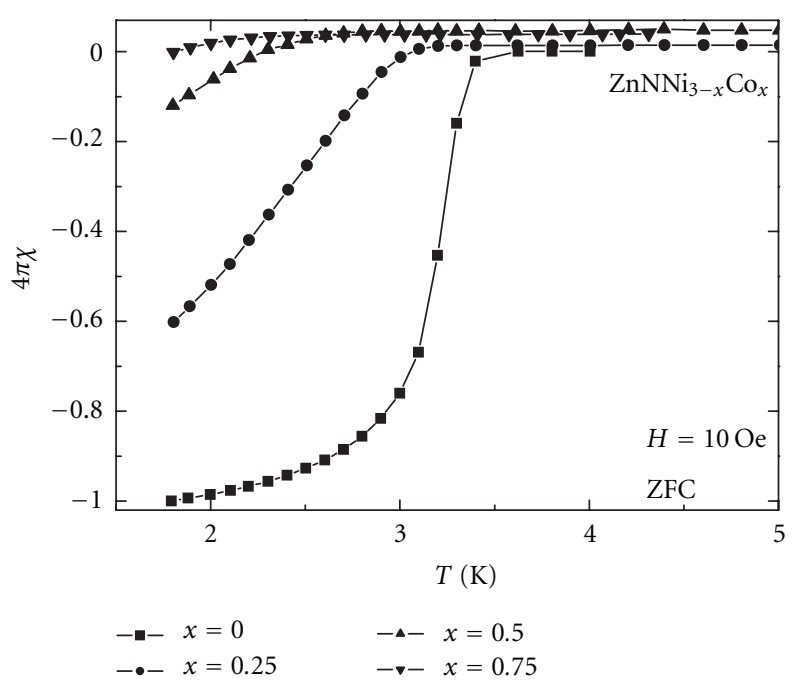

FIgURE 2: Temperature dependence of magnetic susceptibility, $\chi$, normalized by $1 / 4 \pi$ for $\mathrm{ZnNNi}_{3-x} \mathrm{Co}_{x}$ under 10 Oe between $1.8 \mathrm{~K}$ and $5 \mathrm{~K}$ obtained by the ZFC method.

the origin of this coexistence, we analyzed the samples using EPMA.

Figures 4(a) and 4(b) show the elemental mapping analysis for Ni (Figure 4(a)) and Co (Figure 4(b)) over a $230 \times 230 \mu \mathrm{m}^{2}$ area of the $x=0.25$ sample obtained using an acceleration voltage of $15 \mathrm{kV}$ and probe diameter of $1 \mu \mathrm{m}$. In Figure 4(a), darker blue colors indicate areas deficient in $\mathrm{Ni}$ content. From this figure, it can be seen that there are some blue islands that are tens of micrometers in size and have much less $\mathrm{Ni}$ content than the surrounding areas. On the other hand, in Figure 4(b), areas with brighter red colors indicate that the Co content is enhanced in those regions. Comparing these two figures, it is seen that within the islands with very small Ni content seen in Figure 4(a), the Co content is very large. The chemical composition of these islands was revealed to be $\mathrm{ZnN}_{y} \mathrm{Ni}_{0.6} \mathrm{Co}_{2.4}$ and the volume fraction of the islands can be estimated from image 


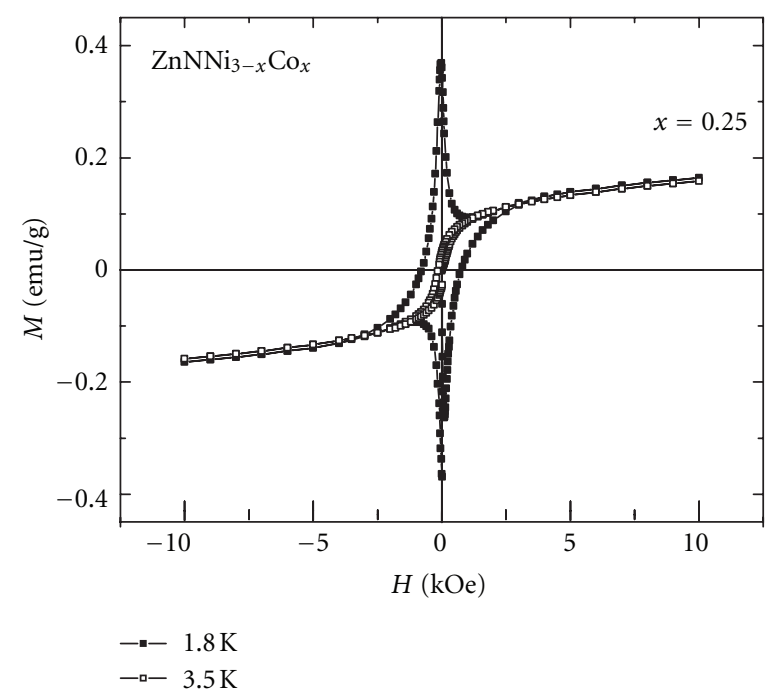

(a)

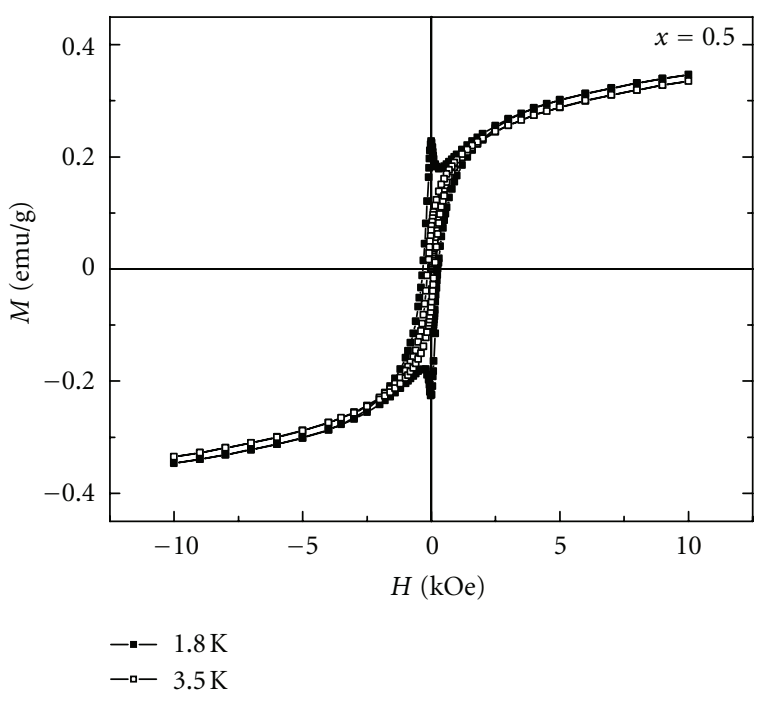

(b)

FIGURE 3: Magnetic field dependence of magnetization at 1.8 and $3.5 \mathrm{~K}$ for $\mathrm{ZnNNi}_{3-x} \mathrm{Co}_{x}$ with (a) $x=0.25$ and (b) $x=0.5$.

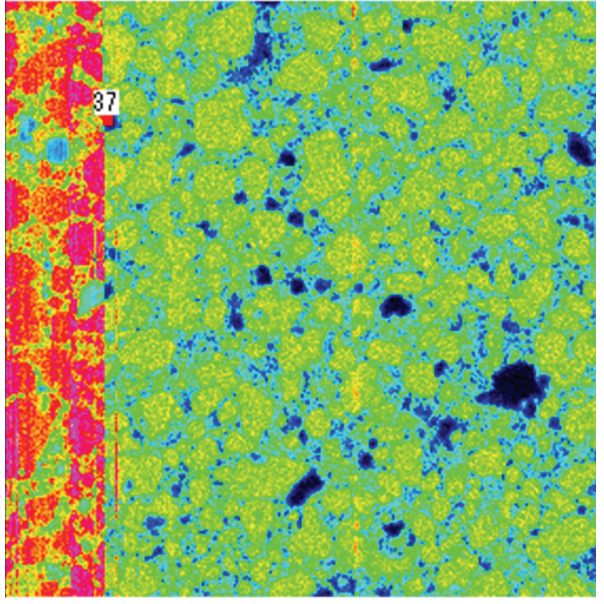

$50 \mu \mathrm{m}$

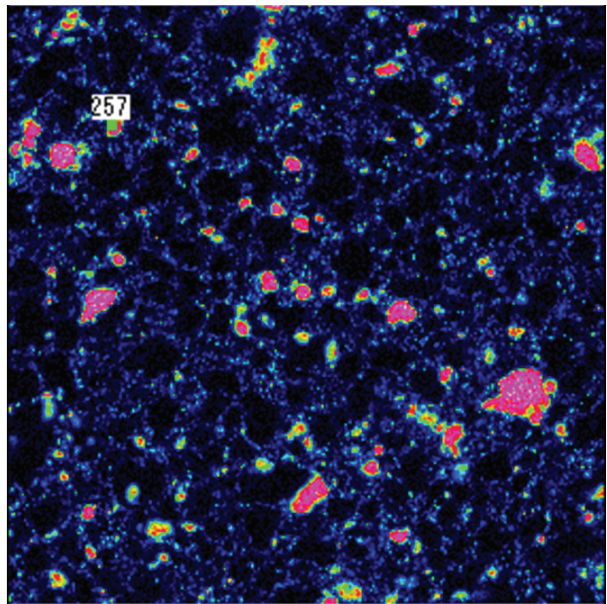

$50 \mu \mathrm{m}$

(a)

(b)

FIGURE 4: Elemental quantity mapping analysis for (a) Ni and (b) Co over a $230 \times 230 \mu \mathrm{m}^{3}$ area for the $x=0.25$ sample with an acceleration voltage of $15 \mathrm{kV}$ and probe diameter of $1 \mu \mathrm{m}$. The red-colored area on the left side of Figure 4(a) is due to instrumental noise.

mapping to be about 5\%. Except for these $\mathrm{ZnN}_{y} \mathrm{Ni}_{0.6} \mathrm{Co}_{2.4}$ islands, the overall chemical composition was found to be nearly pure superconductive $\mathrm{ZnNNi}_{3}$. In order to clarify the magnetic property of $\mathrm{ZnN}_{y} \mathrm{Ni}_{0.6} \mathrm{Co}_{2.4}$, we synthesized a $\mathrm{ZnN}_{y} \mathrm{Ni}_{0.6} \mathrm{Co}_{2.4}$ sample and measured its field-dependent magnetization at $1.8 \mathrm{~K}$ (Figure $5(\mathrm{a})$ ). As clearly seen in Figure 5(a), $\mathrm{ZnN}_{y} \mathrm{Ni}_{0.6} \mathrm{Co}_{2.4}$ is ferromagnetic. In Figure 5(b), $\mathrm{ZnN}_{y} \mathrm{Ni}_{0.6} \mathrm{Co}_{2.4}$ magnetization data is superimposed with the $1.8 \mathrm{~K}$ data shown in Figure $3(\mathrm{a})$; the $\mathrm{ZnN}_{y} \mathrm{Ni}_{0.6} \mathrm{Co}_{2.4}$ magnetization data was scaled by 0.05 , corresponding to the volume fraction of $\mathrm{ZnN}_{y} \mathrm{Ni}_{0.6} \mathrm{Co}_{2.4}$ (5\%) estimated from the EPMA mapping data. It is clear that the ferromagnetic character seen in the $x=0.25$ sample is well explained by the
$5 \%$ reduced magnetization behavior of $\mathrm{ZnN}_{y} \mathrm{Ni}_{0.6} \mathrm{Co}_{2.4}$. It appears that the origin of the coexistence of superconductive and ferromagnetic behavior arises from a chemical phase separation where ferromagnetic $\mathrm{ZnN}_{y} \mathrm{Ni}_{0.6} \mathrm{Co}_{2.4}$ regions are embedded within the superconductive $\mathrm{ZnNNi}_{3}$ background. It should be noted that the overall average composition of this $95 \%-\mathrm{ZnNNi}_{3} / 5 \%-\mathrm{ZnN}_{y} \mathrm{Ni}_{0.6} \mathrm{Co}_{2.4}$ sample is $\mathrm{ZnN}_{y} \mathrm{Ni}_{2.88} \mathrm{Co}_{0.12}$, which corresponds to only half the Co content of the nominal composition of $\mathrm{ZnNNi}_{2.75} \mathrm{Co}_{0.25}$. We suspect that the discrepancy may be explained by the existence of small or thin $\mathrm{ZnN}_{y} \mathrm{Ni}_{0.6} \mathrm{Co}_{2.4}$ portions in the $\mathrm{ZnNNi}_{3}$ grain boundary areas, which we failed to adequately detect by mapping analysis. These small portions may lose 


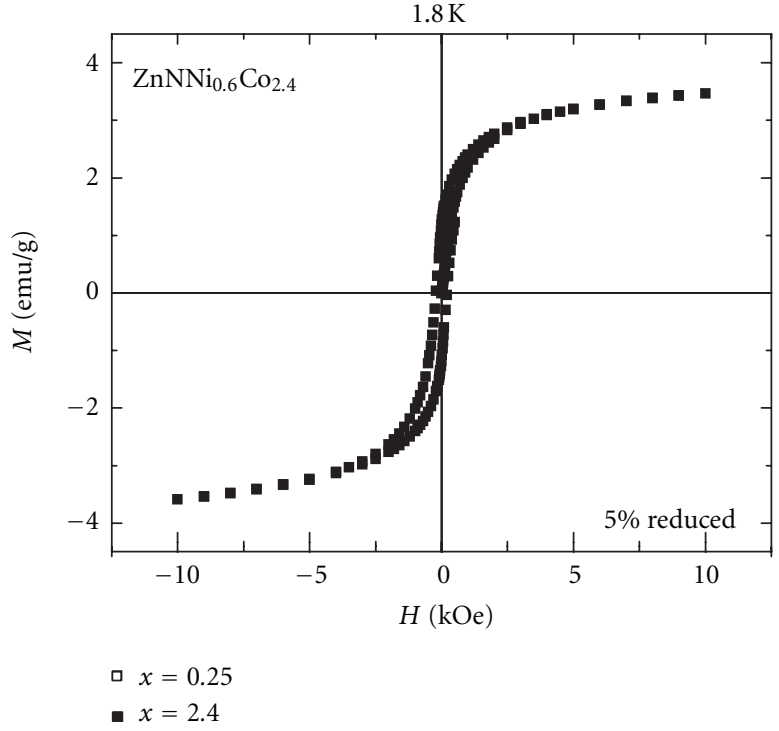

(a)

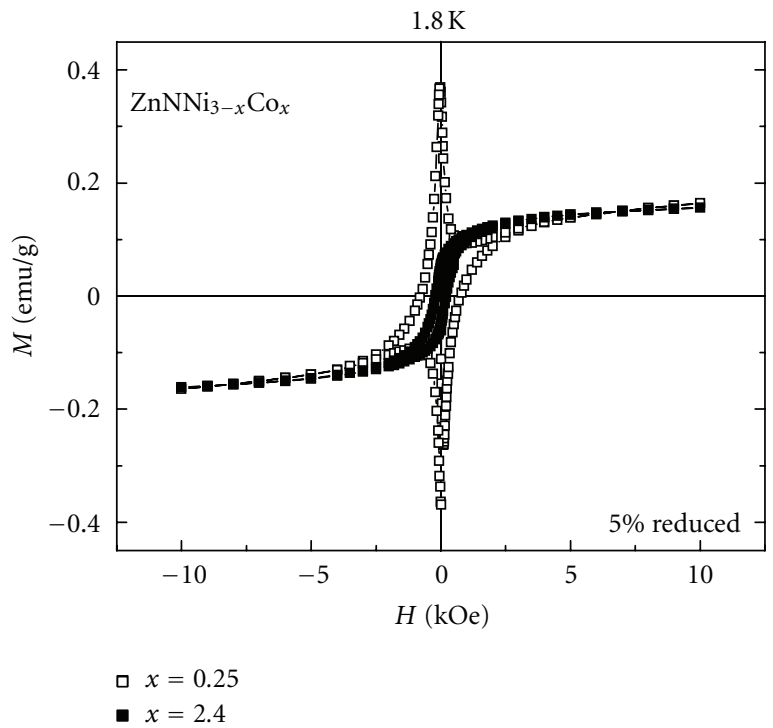

(b)

Figure 5: (a) Magnetic field dependence of magnetization at $1.8 \mathrm{~K}$ for $\mathrm{ZnN}_{y} \mathrm{Ni}_{0.6} \mathrm{Co}_{2.4}$. (b) Magnetic field dependence of magnetization at $1.8 \mathrm{~K}$ for $\mathrm{ZnN}_{y} \mathrm{Ni}_{0.6} \mathrm{Co}_{2.4}$. The magnetization data is scaled by a factor of 0.05 and superimposed with the $1.8 \mathrm{~K}$ data from Figure $3(\mathrm{a})$.

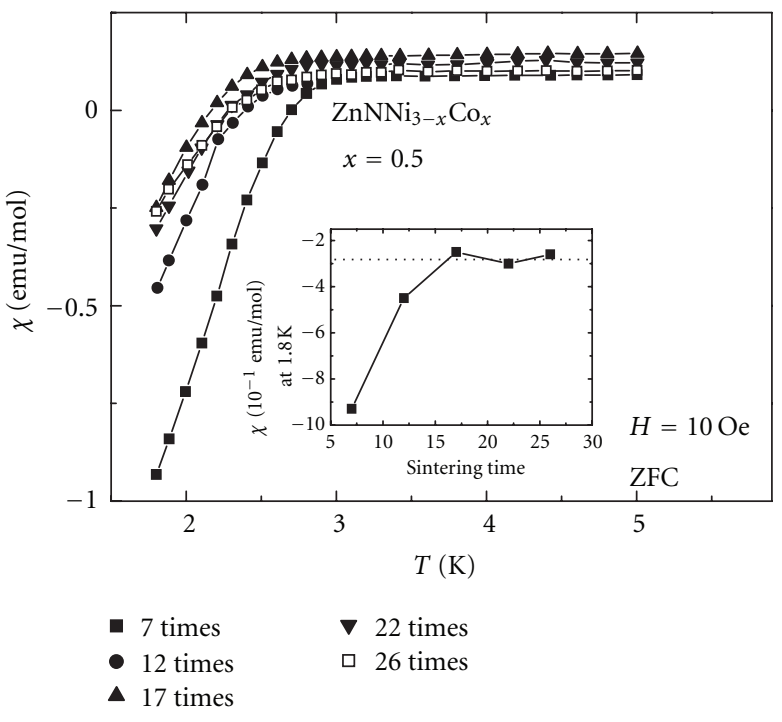

FIGURE 6: Temperature-dependent magnetic susceptibilities of $x=$ 0.5 samples with various numbers of sintering cycles. The inset shows $\chi$ at $1.8 \mathrm{~K}$ as function of sintering cycle number.

their long range ferromagnetic coherence because of their nonbulk morphology. In order to clarify this point, more detailed chemical analysis is needed.

There remains a question of whether the phase separation comes from the intrinsic nature of this compound or from incomplete sample preparation. In Figure 6, the temperature-dependent magnetic susceptibility of $x=0.5$ samples prepared after different numbers of sintering cycles in process (3) $550-600^{\circ} \mathrm{C}$ for $5 \mathrm{~h}$ (see Section 2) is shown.
From this figure, it can be seen that the magnetization value at $1.8 \mathrm{~K}$ increases with increasing number of sintering cycles and almost saturates for the sample after 17 sintering cycles. This indicates that the chemical reaction has gone to completion and that the sample has reached a thermodynamic equilibrium state. Therefore, in this system, more than 17 sintering cycles are enough to achieve complete chemical reaction. The samples used in this study were synthesized with more than 17 sintering cycles; therefore, the two-phase separation cannot be attributed to incomplete synthesis but instead must be intrinsic to the system. It seems that Co ions cannot be substituted into Ni sites in the $x=0.25$ and 0.5 samples, instead, two-phase separation of $\mathrm{ZnNNi}_{3}$ and $\mathrm{ZnN}_{y} \mathrm{Ni}_{0.6} \mathrm{Co}_{2.4}$ arises. In other words, a miscibility gap exists in $\mathrm{ZnN}_{y} \mathrm{Ni}_{3-x} \mathrm{Co}_{x}$ systems for at least $x=0.25$ and 0.5 . In an $\mathrm{Mn}$-doped $\mathrm{ZnNNi}_{3-x} \mathrm{Mn}_{x}$ system synthesized by the same recipe used in the present study, the superconductivity completely disappeared with a tiny amount $(x=0.05)$ of doping, which indicated the formation of a uniform solid solution, even with small doping concentrations [40]. This experimental result also reinforces the peculiar character of the Co-doping system and supports the existence of a miscibility gap. Why does not a uniform solid solution of $\mathrm{ZnN}_{y} \mathrm{Ni}_{3-x} \mathrm{Co}_{x}$ form between the $\mathrm{ZnNNi}_{3}$ and $\mathrm{ZnN}_{y} \mathrm{Co}_{3}$ which have nearly the same crystal structures? As already mentioned, it has been recognized that, in the preset synthesis conditions, the nitrogen content $y$ of $\mathrm{ZnN}_{y} \mathrm{Co}_{3}$ must be about 0.5 [36] unlike $\mathrm{ZnN}_{y} \mathrm{Ni}_{3}(y=1)$. Strictly speaking, the crystal structure of $\mathrm{ZnNNi}_{3}$ is different than $\mathrm{ZnN}_{y} \mathrm{Co}_{3}$ from the viewpoint of nitrogen content. Therefore, it is reasonable to imagine that $\mathrm{ZnN}_{0.5} \mathrm{Co}_{3}$ cannot dissolve into $\mathrm{ZnNNi}_{3}$, even though the overall crystal structure and lattice parameters are almost the same. In contrast, for high $x$ 


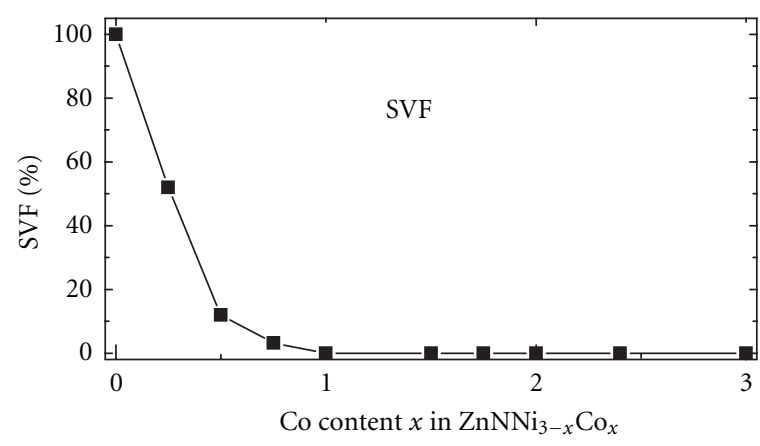

(a)

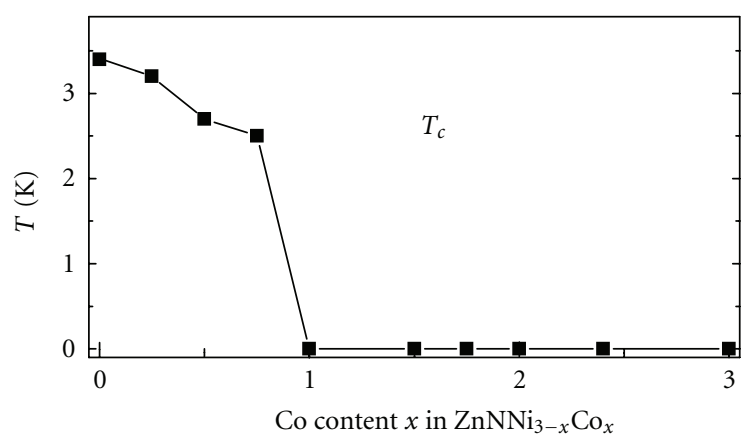

(b)

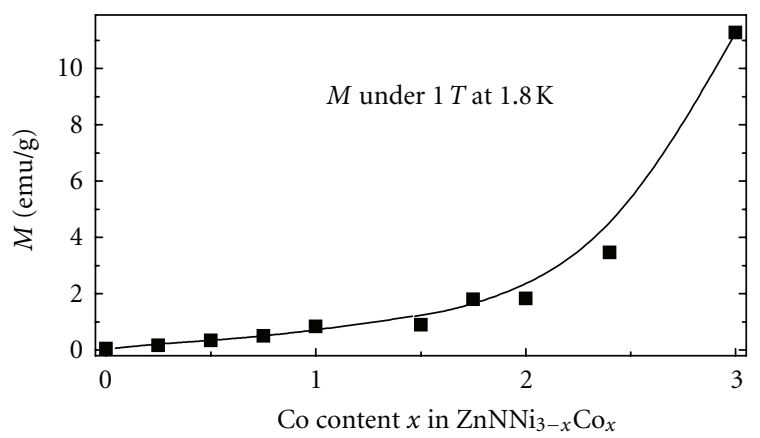

(c)

Figure 7: SVF (a), $T_{c}$ (b), and $M(\mathrm{c})$ as a function of Co content, $x$.

values, homogeneous solid solutions of $\mathrm{ZnN}_{y} \mathrm{Ni}_{3-x} \mathrm{Co}_{x}$ may be realized because the islands of $\mathrm{ZnN}_{y} \mathrm{Ni}_{0.6} \mathrm{Co}_{2.4}$ observed by EPMA mapping seem to be homogeneous within their islands. The nitrogen content $y$ of $\mathrm{ZnN}_{y} \mathrm{Ni}_{0.6} \mathrm{Co}_{2.4}$ is inferred to be 0.5 due to the compositional proximity to $\mathrm{ZnN}_{0.5} \mathrm{Co}_{3}$. A lower nitrogen content $\mathrm{ZnN}_{0.5} \mathrm{Ni}_{3}$ phase can be synthesized under $50 \%-\mathrm{H}_{2}+50 \%-\mathrm{NH}_{3}$ conditions (For synthesizing $\mathrm{ZnN}_{0.5} \mathrm{Ni}_{3}$, the concentration of $\mathrm{NH}_{3}$ gas has to be diluted down to $50 \%$ by $\mathrm{H}_{2}$ gas, while for the case of $\mathrm{ZnNNi}_{3}$, $100 \%-\mathrm{NH}_{3}$ gas is needed.) and may exist as a pseudostable phase under the present synthesis conditions using $100 \%$ $\mathrm{NH}_{3}$ gas. Therefore, it can be supposed that small amounts of $\mathrm{ZnN}_{0.5} \mathrm{Ni}_{3}$ could dissolve into $\mathrm{ZnN}_{0.5} \mathrm{Co}_{3}$ to form the solid solution $\mathrm{ZnN}_{y} \mathrm{Ni}_{3-x} \mathrm{Co}_{x}$ at high $x$ concentrations, with a most likely value of $y=0.5$. If appropriate synthesis conditions were found that allowed the $\mathrm{N}$ content to be 1 for $\mathrm{ZnN}_{y} \mathrm{Co}_{3}$, the formation of uniform solid solutions at all $x$ values could be possible. For example, this may be accomplished by using $\mathrm{NH}_{3}$ gas at more than 1 atm.

In Figure 7, SVF, $T_{c}$, and magnetization values obtained in a $1 T$ field at $1.8 \mathrm{~K}(M)$ are shown as a function of the Co content, $x$. The SVF value decreases linearly as Co content increases up to about 0.5 . This behavior is consistent with a two-phase situation. With linearly increasing $x$, the relative ratio of the superconducting region linearly decreases. $T_{c}$ is nearly constant and suddenly disappears at $x=1 . M$ increases linearly up to about 2 and strongly increases above $x=2$. This implies that the two-phase situation extends up to $x=2$, and at $x>2$ the uniform solid solution $\mathrm{ZnN}_{y} \mathrm{Ni}_{3-x} \mathrm{Co}_{x}$ forms and shows ferromagnetism. However this hypothesis contradicts the experiment because the superconductivity disappears below $x=2$. This discrepancy might be explained by the influence of the magnetic field made by ferromagnetic $\mathrm{ZnN}_{y} \mathrm{Ni}_{0.6} \mathrm{Co}_{2.4}$ regions adjacent to the superconductive $\mathrm{ZnNNi}_{3}$ region under the two-phase situation, which may strongly suppress or wholly destroy the superconductive behavior. In order to clear this point, further investigations employing NMR or $\mu$ SR experiments are needed.

Finally, it should be mentioned that in the two-phase situation a prototype of a ferromagnet-superconductor granular contact device is naturally realized. The nature of the ferromagnet-superconductor grain boundary is expected to be good because the ferromagnetic $\mathrm{ZnN}_{y} \mathrm{Ni}_{0.6} \mathrm{Co}_{2.4}$ and superconductive $\mathrm{ZnNNi}_{3}$ have almost the same crystal structure and lattice constant. This indicates the possibility for use in $\pi$-junction quantum bit and magnetoresistance devices and similar applications by tuning the morphological characteristics of the contact boundary, such as contact strength, shape of the boundary, and each domain size. These parameters may be controllable within conventional solid state reaction techniques by optimizing synthesis conditions such as temperature, sintering time, and nitrogen partial pressure, without the special equipment used in producing thin film devices.

\section{Conclusion}

It has been revealed that, in $\mathrm{ZnN}_{y} \mathrm{Ni}_{3-x} \mathrm{Co}_{x}$ systems with $0<x<0.75$, instead of forming uniform solid solutions, micrometric scale ferromagnetic $\mathrm{ZnN}_{y} \mathrm{Ni}_{0.6} \mathrm{Co}_{2.4}$ domains 
embed within a superconductive $\mathrm{ZnNNi}_{3}$ bulk, showing chemical phase separation of superconductive $\mathrm{ZnNNi}_{3}$ and ferromagnetic $\mathrm{ZnN}_{y} \mathrm{Ni}_{0.6} \mathrm{Co}_{2.4}$. Our results suggest that, for $0.75<x<2$, two-phase separation persists, but the superconducting region is strongly suppressed or almost destroyed possibly by the magnetic field produced by surrounding ferromagnetic regions. Above $x>2$, the uniform solid solution $\mathrm{ZnN}_{y} \mathrm{Ni}_{3-x} \mathrm{Co}_{x}$ (with most likely $y=0.5$ ) forms, and in this compositional region the system shows long range ferromagnetism. The two-phase separation nature is intrinsic to the system, reflecting the existence of a miscibility gap in $\mathrm{ZnN}_{y} \mathrm{Ni}_{3-x} \mathrm{Co}_{x}$ with $0<x<0.75$ and suggestively with $0.75<x<2$. The origin of this unexpected chemical phase separation is probably due to the differences in stable nitrogen content between $\mathrm{ZnN}_{y} \mathrm{Ni}_{3}(y=1)$ and $\mathrm{ZnN}_{y} \mathrm{Ni}_{0.6} \mathrm{Co}_{2.4}(y=0.5)$. By taking advantage of this twophase situation, useful devices requiring high-quality granular contacts between superconductors and ferromagnets could be produced.

\section{Acknowledgment}

This work was partly supported by Research Institute and Instrumental Analysis Center of Yokohama National University.

\section{References}

[1] T. He, Q. Huang, A. P. Ramirez et al., "Superconductivity in the non-oxide perovskite $\mathrm{MgCNi}_{3}$," Nature, vol. 411, no. 6833, pp. 54-56, 2001.

[2] H. Ronser, R. Weht, M. D. Johannes, W. E. Pickett, and E. Tosatti:, "Superconductivity near Ferromagnetism in $\mathrm{MgCNi}_{3}$," Physical Review Letters, vol. 88, no. 2, Article ID 027001, 2002.

[3] P. M. Singer, T. Imai, T. He, M. A. Hayward, and R. J. Cava,

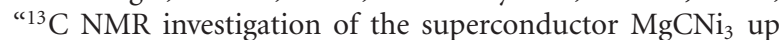
to $800 \mathrm{~K}$," Physical Review Letters, vol. 87, no. 25, Article ID 257601, 2001.

[4] J.-Y. Lin, P. L. Ho, H. L. Huang et al., "BCS-like superconductivity in $\mathrm{MgCNi}_{3}$," Physical Review B, vol. 67, Article ID 052501, 4 pages, 2003.

[5] Z. Q. Mao, M. M. Rosario, K. D. Nelson et al., "Experimental determination of superconducting parameters for the intermetallic perovskite superconductor $\mathrm{MgCNi}_{3}$," Physical Review B, vol. 67, Article ID 0945021, 2003.

[6] L. Shan, K. Xia, Z. Y. Liu et al., "Influence of carbon concentration on the superconductivity in $\mathrm{MgC}_{x} \mathrm{Ni}_{3}$," Physical Review B, vol. 68, no. 2, Article ID 024523, 5 pages, 2003.

[7] L. Shan, H. J. Tao, H. Gao et al., "s-wave pairing in $\mathrm{MgCNi}_{3}$ revealed by point contact tunneling," Physical Review B, vol. 68, no. 14, Article ID 144510, 5 pages, 2003.

[8] R. Prozorov, A. Snezhko, T. He, and R. J. Cava, Physical Review $B$, vol. 68, Article ID 1805021, 2003.

[9] D. P. Young, M. Moldovan, and P. W. Adams:, "Scaling behavior of the critical current density in $\mathrm{MgCNi}_{3}$ microfibers," Physical Review B, vol. 70, no. 6, Article ID 064508, 2004.

[10] A. Wälte, G. Fuchs, K. H. Müller et al., "Evidence for strong electron-phonon coupling in $\mathrm{MgCNi}_{3}$," Physical Review B, vol. 70, no. 17, Article ID 174503, 18 pages, 2004.
[11] L. Shan, Z. Y. Liu, Z. A. Ren, G. C. Che, and H. H. Wen, "Competition between BCS superconductivity and ferromagnetic spin fluctuations in $\mathrm{MgCNi}_{3}$," Physical Review B, vol. 71, no. 14, Article ID 144516, 6 pages, 2005.

[12] M. Uehara, T. Yamazaki, T. Kôri, T. Kashida, Y. Kimishima, and K. Ohishi, "Magnetism on $\mathrm{Mg}_{1-x} \mathrm{Zn}_{x} \mathrm{C}_{y} \mathrm{Ni}_{3}$," Journal of Physics and Chemistry of Solids, vol. 68, no. 11, pp. 2178-2182, 2007.

[13] P. Diener, P. Rodière, T. Klein et al., "S-wave superconductivity probed by measuring magnetic penetration depth and lower critical field of $\mathrm{MgCNi}_{3}$ single crystals," Physical Review B, vol. 79, no. 22, Article ID 220508, 2009.

[14] Z. Pribulová, J. Kačmarčík, C. Marcenat et al., "Superconducting energy gap in $\mathrm{MgCNi}_{3}$ single crystals: point-contact spectroscopy and specific-heat measurements," Physical Review B, vol. 83, no. 10, Article ID 104511, 7 pages, 2011.

[15] M. S. Park, J. S. Giim, S. H. Park, Y. W. Lee, S. I. Lee, and E. J. Choi, "Physical properties of $\mathrm{ZnCNi}_{3}$ : comparison with superconducting $\mathrm{MgCNi}_{3}$," Superconductor Science and Technology, vol. 17, no. 2, pp. 274-277, 2004.

[16] M. Uehara, T. Amano, S. Takano, T. Kôri, T. Yamazaki, and Y. Kimishima, "Chemical pressure effect on the superconductor $\mathrm{MgCNi}_{3}$," Physica C, vol. 440, no. 1-2, pp. 6-9, 2006.

[17] M. Uehara, T. Yamazaki, T. Kôri, T. Kashida, Y. Kimishima, and I. Hase, "Superconducting properties of $\mathrm{CdCNi}_{3}$," Journal of the Physical Society of Japan, vol. 76, Article ID 0347141, 5 pages, 2007.

[18] F. R. de Boer, C. J. Schinkel, J. Biesterbos, and S. Proost, "Exchange-enhanced paramagnetism and weak ferromagnetism in the $\mathrm{Ni}_{3} \mathrm{Al}$ and $\mathrm{Ni}_{3} \mathrm{Ga}$ phases; Giant moment inducement in Fe-doped $\mathrm{Ni}_{3} \mathrm{Ga}$," Journal of Applied Physics, vol. 40, no. 3, pp. 1049-1055, 1969.

[19] A. F. Dong, G. C. Che, W. W. Huang, S. L. Jia, H. Chen, and Z. X. Zhao, "Synthesis and physical properties of $\mathrm{AlCNi}_{3}$," Physica C, vol. 422, no. 1-2, pp. 65-69, 2005.

[20] P. Tong, Y. P. Sun, X. B. Zhu, and W. H. Song, "Synthesis and physical properties of antiperovskite-type compound $\mathrm{In}_{0.95} \mathrm{CNi}_{3}$," Solid State Communications, vol. 141, no. 6, pp. 336-340, 2007.

[21] P. Tong, Y. P. Sun, X. B. Zhu, and W. H. Song:, "Strong electron-electron correlation in the antiperovskite compound $\mathrm{GaCNi}_{3}$," Physical Review B, vol. 73, Article ID 2451061, 2006.

[22] P. Tong, Y. P. Sun, X. B. Zhu, and W. H. Song, "Strong spin fluctuations and possible non-Fermi-liquid behavior in $\mathrm{AlCNi}_{3}$," Physical Review B, vol. 74, no. 22, Article ID 224416, 7 pages, 2006.

[23] W. H. Cao, B. He, C. Z. Liao, L. H. Yang, L. M. Zeng, and C. Dong:, "Preparation and properties of antiperovskite-type nitrides: $\mathrm{InNNi}_{3}$ and $\mathrm{InNCo}_{3}$," Journal of Solid State Chemistry, vol. 182, no. 12, pp. 3353-3357, 2009.

[24] B. He, C. Dong, L. Yang, L. Ge, and H. Chen, "Preparation and physical properties of antiperovskite-type compounds CdNCoCdNCo ${ }_{3-z} \mathrm{Ni}_{z} 0 \leq z \leq 3$," Journal of Solid State Chemistry, vol. 184, no. 8, pp. 1939-1945, 2011.

[25] B. He, C. Dong, L. Yang, L. Ge, L. Mu, and C. Chen, "Preparation and the physical properties of antiperovskite-type compounds $\mathrm{Cd}_{1-x} \operatorname{In}_{x} \mathrm{NNi}_{3}(0 \leq x \leq 0.2)$ and $\mathrm{Cd}_{1-y} \mathrm{Cu}_{y} \mathrm{NNi}_{3}$ $(0 \leq y \leq 0.2)$," Chinese Physics B, vol. 21, no. 4, Article ID 047401, 2012.

[26] M. Y. Duan, J. J. Tan, G. F. Ji, X. R. Chen, and J. Zhu, "Elastic and Thermodynamic Properties of Anti-Perovskite Type Superconductor $\mathrm{MCNi}_{3}(\mathrm{M}=\mathrm{Zn}, \mathrm{Cd})$," Acta Physica Polonica $A$, vol. 118, p. 652, 2010. 
[27] M. D. Johannes and W. E. Pickett, "Electronic structure of $\mathrm{ZnCNi}_{3}$," Physical Review B, vol. 70, no. 6, Article ID 060507, 4 pages, 2004.

[28] P. Joseph and P. P. Singh, "A first-principles comparison of the electronic properties of $\mathrm{MgC}_{y} \mathrm{Ni}_{3}$ and $\mathrm{ZnC}_{y} \mathrm{Ni}_{3}$ alloys," Journal of Physics: Condensed Matter, vol. 18, no. 23, p. 5333, 2006.

[29] M. Sieberer, P. Mohn, and J. Redinger, "Role of carbon in $\mathrm{AlCNi}_{3}$ and $\mathrm{GaCNi}_{3}$ : a density functional theory study," Physical Review B, vol. 75, no. 2, Article ID 024431, 2007.

[30] I. R. Shein, V. V. Bannikov, and A. L. Ivanovskii, "Structural, elastic and electronic properties of superconducting anti-perovskites $\mathrm{MgCNi}_{3}, \mathrm{ZnCNi}_{3}$ and $\mathrm{CdCNi}_{3}$ from first principles," Physica C, vol. 468, no. 1, pp. 1-6, 2008.

[31] S. Bağcl, S. Duman, H. M. Tütüncü, and G. P. Srivastava, "Ground state, phonon spectrum, and superconducting properties of the nonoxide perovskite $\mathrm{CdCNi}_{3}$," Physical Review B, vol. 78, no. 17, Article ID 174504, 6 pages, 2008.

[32] C. Li, W. G. Chen, F. Wang et al., "Epitaxial growth of fcc$\mathrm{Co}_{x} \mathrm{Ni}_{100-x}$ thin films on $\mathrm{MgO}(110)$ single-crystal substrates," Journal of Applied Physics, vol. 105, no. 12, Article ID 123921, 4 pages, 2009.

[33] S. Q. Wu, Z. F. Hou, and Z. Z. Zhu, "Elastic properties and electronic structures of $\mathrm{CdCNi}_{3}$ : a comparative study with $\mathrm{MgCNi}_{3}$," Solid State Sciences, vol. 11, no. 1, pp. 251-258, 2009.

[34] M. Uehara, A. Uehara, K. Kozawa, and Y. Kimishima, "New antiperovskite-type superconductor $\mathrm{ZnN}_{y} \mathrm{Ni}_{3}$," Journal of the Physical Society of Japan, vol. 78, no. 3, Article ID 033702, 4 pages, 2009.

[35] M. Uehara, A. Uehara, K. Kozawa, T. Yamazaki, and Y. Kimishima, "New antiperovskite superconductor $\mathrm{ZnNNi}_{3}$, and related compounds $\mathrm{CdNNi}_{3}$ and $\mathrm{InNNi}_{3}$, , Physica $C$, vol. 470, no. 1, pp. S688-S690, 2010.

[36] H. H. Stadelmaier and T. S. Yun, "Alloys of nitorgen and the transition metals $\mathrm{Mn}, \mathrm{Fe}, \mathrm{Co}$ and $\mathrm{Ni}$ with $\mathrm{Mg}, \mathrm{Al}, \mathrm{Zn}$ and Cd," Zeitschrift für Metallkunde, vol. 52, pp. 477-480, 1961.

[37] R. Juza and W. Sachze, "Zur Kenntnis des Systems Nickel/ Stickstoff. Metallamide und Metallnitride, 12. Mitt," Zeitschrift für anorganische und allgemeine Chemie, vol. 251, no. 2, pp. 201-212, 1943.

[38] N. Saegusa, T. Tsukagoshi, E. Kita, and A. Tasaki, "Magnetic properties of iron-nitride particles prepared with gas evaporation method," IEEE Transactions on Magnetics, vol. 19, no. 5, pp. 1629-1631, 1983.

[39] H. Jacobs, D. Rechenbach, and U. Zachwieja, "Structure determination of $\gamma^{\prime}-\mathrm{Fe}_{4} \mathrm{~N}$ and $\varepsilon-\mathrm{Fe}_{3} \mathrm{~N}$," Journal of Alloys and Compounds, vol. 227, no. 1, pp. 10-17, 1995.

[40] M. Uehara, K. Kozawa, M. Ohashi et al., "Ni-site doping effect of new antiperovskite superconductor $\mathrm{ZnNNi}_{3}$," Journal of Physics: Conference Series, vol. 400, part 2, Article ID 022128, 2012. 

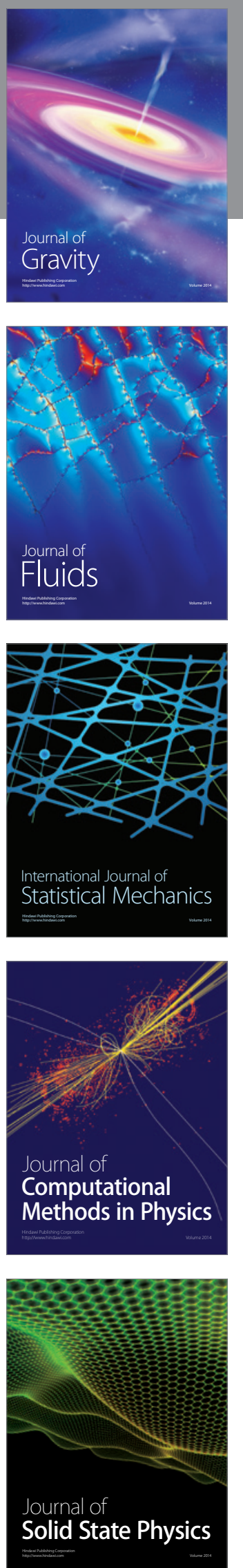

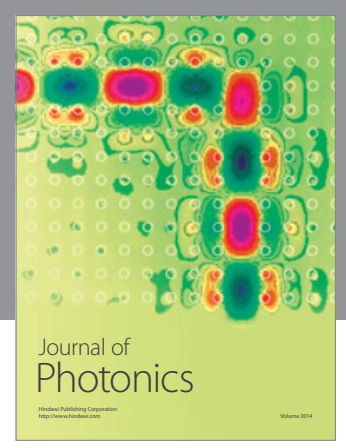

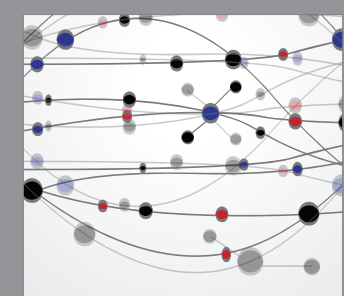

The Scientific World Journal
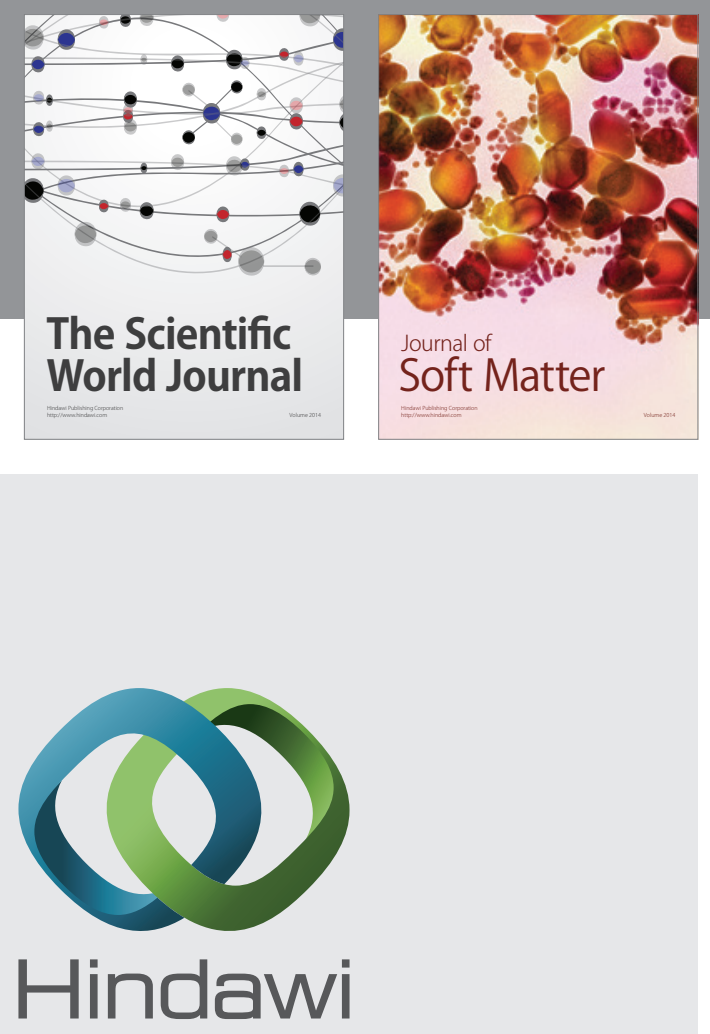

Submit your manuscripts at

http://www.hindawi.com
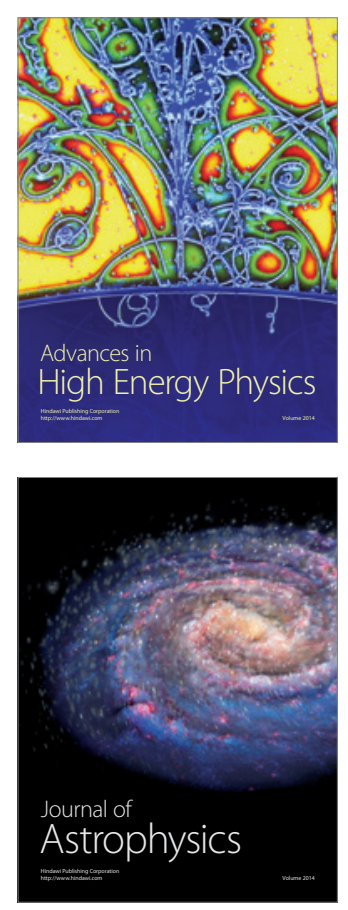
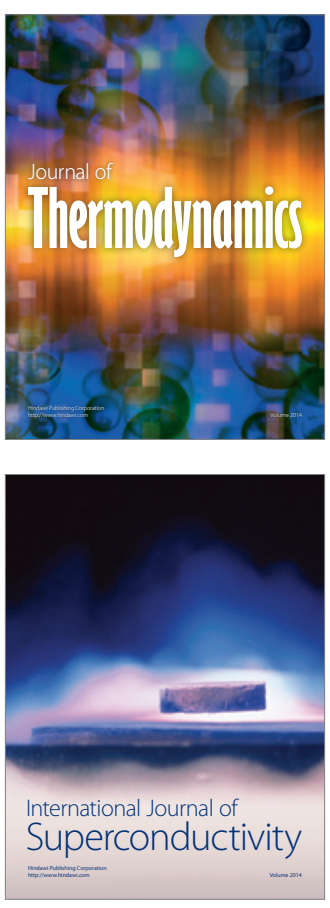
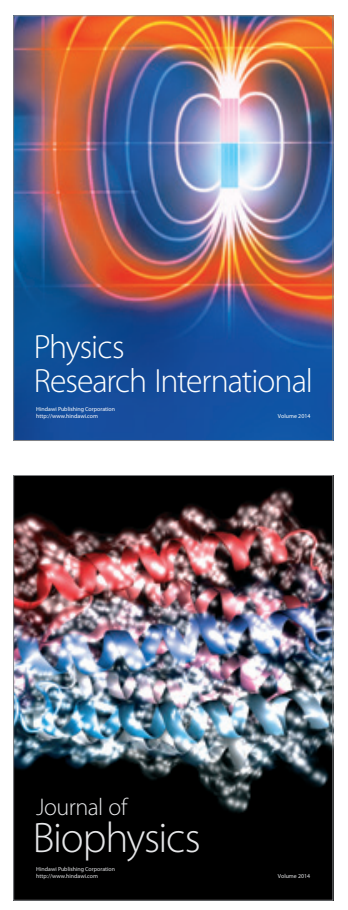
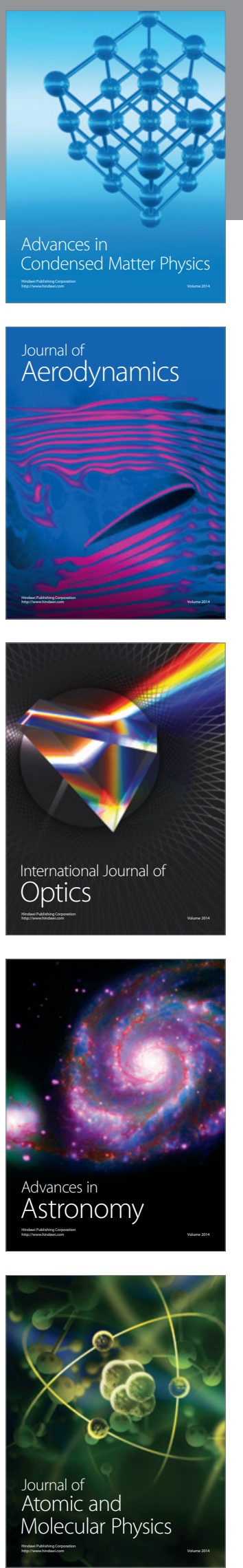